PHYSICAL REVIEW D 92, 019903(E) (2015)

\title{
Erratum: Muons in air showers at the Pierre Auger Observatory: Measurement of atmospheric production depth [Phys. Rev. D 90, 012012 (2014)]
}

A. Aab, P. Abreu, M. Aglietta, M. Ahlers, E. J. Ahn, I. Al Samarai, I. F. M. Albuquerque, I. Allekotte, J. Allen, P. Allison, A. Almela, J. Alvarez Castillo, J. Alvarez-Muñiz, R. Alves Batista, M. Ambrosio, A. Aminaei, L. Anchordoqui, S. Andringa, C. Aramo, F. Arqueros, H. Asorey, P. Assis, J. Aublin, M. Ave, M. Avenier, G. Avila, A. M. Badescu, K. B. Barber, J. Bäuml, C. Baus, J. J. Beatty, K. H. Becker, J. A. Bellido, C. Berat, X. Bertou, P. L. Biermann, P. Billoir, F. Blanco, M. Blanco, C. Bleve, H. Blümer, M. Boháčová, D. Boncioli, C. Bonifazi, R. Bonino, N. Borodai, J. Brack,

I. Brancus, P. Brogueira, W. C. Brown, P. Buchholz, A. Bueno, M. Buscemi, K. S. Caballero-Mora, B. Caccianiga,

L. Caccianiga, M. Candusso, L. Caramete, R. Caruso, A. Castellina, G. Cataldi, L. Cazon, R. Cester, A. G. Chavez, S. H. Cheng, A. Chiavassa, J. A. Chinellato, J. Chudoba, M. Cilmo, R. W. Clay, G. Cocciolo, R. Colalillo, L. Collica, M. R. Coluccia, R. Conceição, F. Contreras, M. J. Cooper, S. Coutu, C. E. Covault, A. Criss, J. Cronin, A. Curutiu, R. Dallier, B. Daniel, S. Dasso, K. Daumiller, B. R. Dawson, R. M. de Almeida, M. De Domenico, S. J. de Jong, J. R. T. de Mello Neto, I. De Mitri, J. de Oliveira, V. de Souza, L. del Peral, O. Deligny, H. Dembinski, N. Dhital, C. Di Giulio, A. Di

Matteo, J. C. Diaz, M. L. Díaz Castro, P. N. Diep, F. Diogo, C. Dobrigkeit, W. Docters, J. C. D’Olivo, P. N. Dong, A. Dorofeev, Q. Dorosti Hasankiadeh, M. T. Dova, J. Ebr, R. Engel, M. Erdmann, M. Erfani, C. O. Escobar, J. Espadanal, A. Etchegoyen, P. Facal San Luis, H. Falcke, K. Fang, G. Farrar, A. C. Fauth, N. Fazzini, A. P. Ferguson, M. Fernandes, B. Fick, J. M. Figueira, A. Filevich, A. Filipčič, B. D. Fox, O. Fratu, U. Fröhlich, B. Fuchs, T. Fuji, R. Gaior, B. García, S. T. Garcia Roca, D. Garcia-Gamez, D. Garcia-Pinto, G. Garilli, A. Gascon Bravo, F. Gate, H. Gemmeke, P. L. Ghia, U. Giaccari, M. Giammarchi, M. Giller, C. Glaser, H. Glass, F. Gomez Albarracin, M. Gómez Berisso, P. F. Gómez Vitale, P. Gonçalves, J. G. Gonzalez, B. Gookin, A. Gorgi, P. Gorham, P. Gouffon, S. Grebe, N. Griffith, A. F. Grillo, T. D. Grubb, Y. Guardincerri, F. Guarino, G. P. Guedes, P. Hansen, D. Harari, T. A. Harrison, J. L. Harton, A. Haungs, T. Hebbeker, D. Heck, P. Heimann, A. E. Herve, G. C. Hill, C. Hojvat, N. Hollon, E. Holt, P. Homola, J. R. Hörandel, P. Horvath, M. Hrabovský, D. Huber, T. Huege, A. Insolia, P. G. Isar, K. Islo, I. Jandt, S. Jansen, C. Jarne, M. Josebachuili, A. Kääpä,

O. Kambeitz, K. H. Kampert, P. Kasper, I. Katkov, B. Kégl, B. Keilhauer, A. Keivani, E. Kemp, R. M. Kieckhafer, H. O. Klages, M. Kleifges, J. Kleinfeller, R. Krause, N. Krohm, O. Krömer, D. Kruppke-Hansen, D. Kuempel, N. Kunka, G. La Rosa, D. LaHurd, L. Latronico, R. Lauer, M. Lauscher, P. Lautridou, S. Le Coz, M. S. A. B. Leão, D. Lebrun,

P. Lebrun, M. A. Leigui de Oliveira, A. Letessier-Selvon, I. Lhenry-Yvon, K. Link, R. López, A. Lopez Agüera,

K. Louedec, J. Lozano Bahilo, L. Lu, A. Lucero, M. Ludwig, H. Lyberis, M. C. Maccarone, M. Malacari, S. Maldera, J. Maller, D. Mandat, P. Mantsch, A. G. Mariazzi, V. Marin, I. C. Mariş, G. Marsella, D. Martello, L. Martin, H. Martinez, O. Martínez Bravo, D. Martraire, J. J. Masías Meza, H. J. Mathes, S. Mathys, A. J. Matthews, J. Matthews, G. Matthiae, D. Maurel, D. Maurizio, E. Mayotte, P. O. Mazur, C. Medina, G. Medina-Tanco, M. Melissas, D. Melo, E. Menichetti, A. Menshikov, S. Messina, R. Meyhandan, S. Mićanović, M. I. Micheletti, L. Middendorf, I. A. Minaya, L. Miramonti, B. Mitrica, L. Molina-Bueno, S. Mollerach, M. Monasor, D. Monnier Ragaigne, F. Montanet, C. Morello, J. C. Moreno, M. Mostafá, C. A. Moura, M. A. Muller, G. Müller, M. Münchmeyer, R. Mussa, G. Navarra, S. Navas, P. Necesal,

L. Nellen, A. Nelles, J. Neuser, M. Niechciol, L. Niemietz, T. Niggemann, D. Nitz, D. Nosek, V. Novotny, L. Nožka,

L. Ochilo, A. Olinto, M. Oliveira, M. Ortiz, N. Pacheco, D. Pakk Selmi-Dei, M. Palatka, J. Pallotta, N. Palmieri,

P. Papenbreer, G. Parente, A. Parra, S. Pastor, T. Paul, M. Pech, J. Pȩkala, R. Pelayo, I. M. Pepe, L. Perrone, R. Pesce, E. Petermann, C. Peters, S. Petrera, A. Petrolini, Y. Petrov, R. Piegaia, T. Pierog, P. Pieroni, M. Pimenta, V. Pirronello, M. Platino, M. Plum, A. Porcelli, C. Porowski, R. R. Prado, P. Privitera, M. Prouza, V. Purrello, E. J. Quel, S. Querchfeld, S. Quinn, J. Rautenberg, O. Ravel, D. Ravignani, B. Revenu, J. Ridky, S. Riggi, M. Risse, P. Ristori,

V. Rizi, J. Roberts, W. Rodrigues de Carvalho, I. Rodriguez Cabo, G. Rodriguez Fernandez, J. Rodriguez Rojo, M. D. Rodríguez-Frías, G. Ros, J. Rosado, T. Rossler, M. Roth, E. Roulet, A. C. Rovero, C. Rühle, S. J. Saffi, A. Saftoiu, F. Salamida, H. Salazar, A. Saleh, F. Salesa Greus, G. Salina, F. Sánchez, P. Sanchez-Lucas, C. E. Santo, E. Santos, E. M. Santos, F. Sarazin, B. Sarkar, R. Sarmento, R. Sato, N. Scharf, V. Scherini, H. Schieler, P. Schiffer, A. Schmidt, O. Scholten, H. Schoorlemmer, P. Schovánek, A. Schulz, J. Schulz, S. J. Sciutto, A. Segreto, M. Settimo, A. Shadkam, R. C. Shellard, I. Sidelnik, G. Sigl, O. Sima, A. Śmiałkowski, R. Šmída, G. R. Snow, P. Sommers, J. Sorokin, R. Squartini, Y. N. Srivastava, S. Stanič, J. Stapleton, J. Stasielak, M. Stephan, A. Stutz, F. Suarez, T. Suomijärvi, A. D. Supanitsky, M. S. Sutherland, J. Swain, Z. Szadkowski, M. Szuba, O. A. Taborda, A. Tapia, M. Tartare, N. T. Thao, V. M. Theodoro, J. Tiffenberg, C. Timmermans, C. J. Todero Peixoto, G. Toma, L. Tomankova, B. Tomé, A. Tonachini, G. Torralba Elipe, D. Torres Machado, P. Travnicek, E. Trovato, M. Tueros, R. Ulrich, M. Unger, M. Urban, J. F. Valdés Galicia, I. Valiño, L. Valore, G. van Aar, A. M. van den Berg, S. van Velzen, A. van Vliet, E. Varela, B. Vargas Cárdenas, G. Varner, J. R. Vázquez, R. A. Vázquez, D. Veberič, V. Verzi, J. Vicha, M. Videla, L. Villaseñor, B. Vlcek, S. Vorobiov, H. Wahlberg, O. Wainberg, D. Walz, A. A. Watson, M. Weber, K. Weidenhaupt, A. Weindl, F. Werner, B. J. Whelan, A. Widom, 
L. Wiencke, B. Wilczyńska, H. Wilczyński, M. Will, C. Williams, T. Winchen, D. Wittkowski, B. Wundheiler, S. Wykes, T. Yamamoto, T. Yapici, P. Younk, G. Yuan, A. Yushkov, B. Zamorano, E. Zas, D. Zavrtanik, M. Zavrtanik, I. Zaw, A. Zepeda, J. Zhou, Y. Zhu, M. Zimbres Silva, and M. Ziolkowski

(Pierre Auger Collaboration)

(Received 9 June 2015; published 20 July 2015)

Full simulations of extensive air showers require large amounts of CPU time and disk space. Consequently, the generation of Monte Carlo events calls for the implementation of a thinning algorithm. A procedure to undo the thinning is thus mandatory to have a fair representation of the signals collected by the water Cherenkov detectors. The strategy consists in the estimation of the distributions of particles at the position of the detectors by averages over extended areas around this position. Following a thorough revision of the unthinning algorithm used in our simulations [1], we discovered that the value chosen for the sampling area was not optimal and introduced an underestimation of the muon delay with respect to the

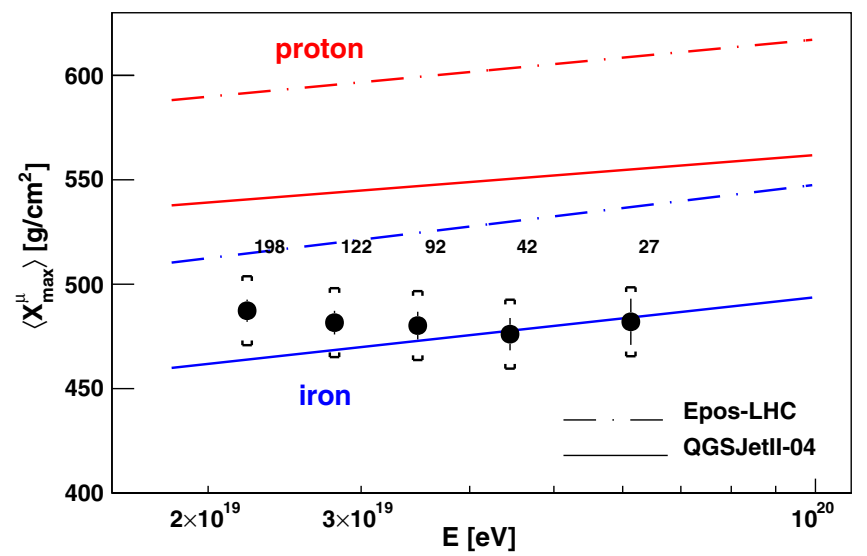

FIG. 1 (color online). $\left\langle X_{\max }^{\mu}\right\rangle$ as a function of energy. The prediction of different hadronic models for proton and iron are shown. Numbers indicate the number of events in each energy bin and brackets represent the systematic uncertainty.
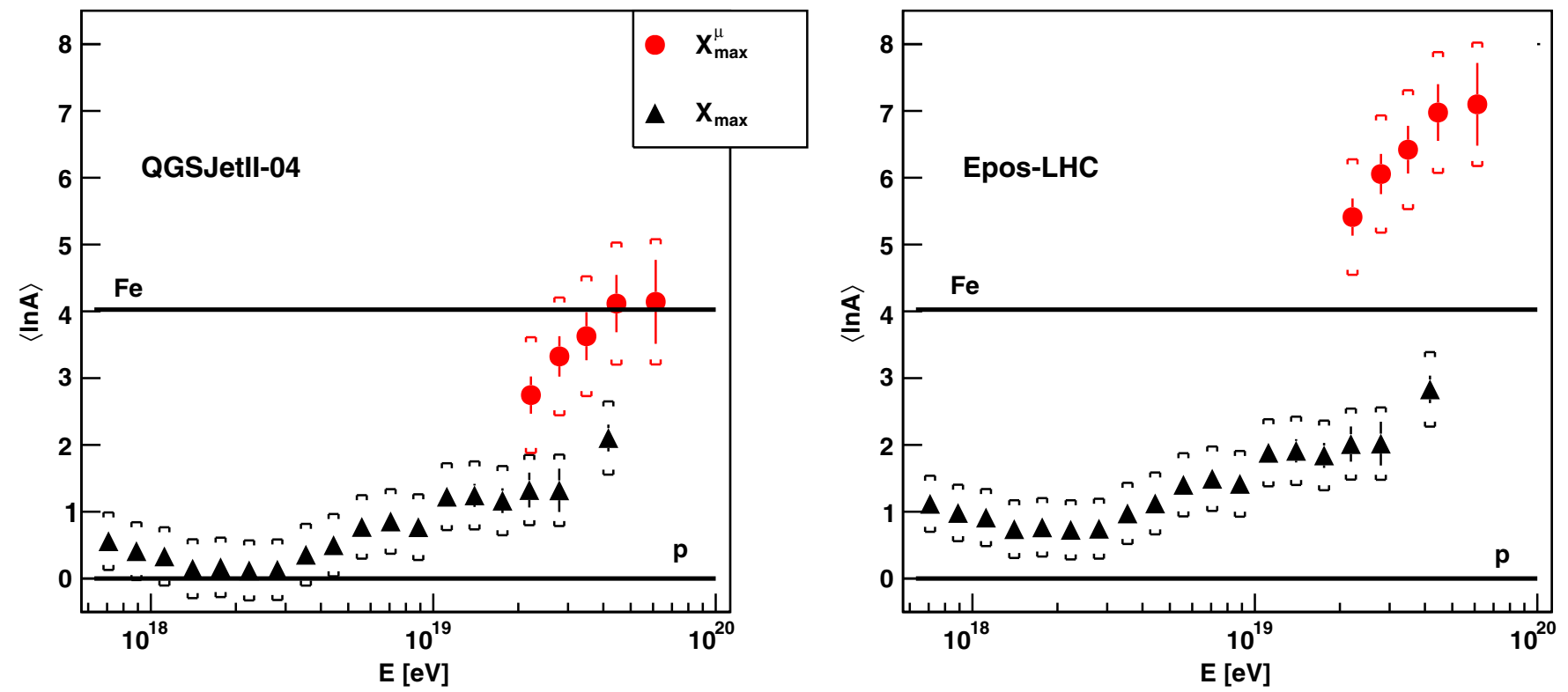

FIG. 2 (color online). Conversion of $\left\langle X_{\max }^{\mu}\right\rangle$ (circles) and $\left\langle X_{\max }\right\rangle$ (triangles) to $\langle\ln A\rangle$, as a function of energy. On the left (right) plot we use QGSJETII-04 (EPOS-LHC) as the reference hadronic model. Brackets correspond to the systematic uncertainties. 
arrival time of the shower front. After adjusting that resampling variable to a more appropriate value, it turns out that the average value of $X_{\max }^{\mu}$ shows a net bias of $24 \mathrm{~g} / \mathrm{cm}^{2}$. This bias is corrected for in simulations in order to obtain an unbiased analysis. Hence in the published article, Fig. 7 remains unchanged. However, this correction has to be accounted for in data (i.e., all measured $X_{\max }^{\mu}$ values must be reduced by an amount equal to the estimated bias). As a result of this, Figs. 1 and 2 shown here must supersede Figs. 8 and 9 in the original publication. For the hadronic model Epos-LHC, the mean $\ln A$ values extracted from the measurements of $X_{\max }$ and $X_{\max }^{\mu}$ are incompatible with each other at a level of at least $6 \sigma$. With QGSJETII-04, we obtain compatible values for $\ln A$ within $1.5 \sigma$. Nothing has been modified in the method or the analysis procedure described in the published paper, therefore its physics conclusions remain unchanged.

[1] P. Billoir, A sampling procedure to regenerate particles in a ground detector from a "thinned" air shower simulation output, Astropart. Phys. 30, 270 (2008). 